Syntax Literate: Jurnal Ilmiah Indonesia p-ISSN: 2541-0849

e-ISSN: 2548-1398

Vol. 5, No. 7, Juli 2020

\title{
STRATEGI PENGEMBANGAN EKOWISATA HUTAN MANGROVE PANDANSARI KABUPATEN BREBES UNTUK MENGURANGI KEMISKINAN
}

\author{
Anisa Nur Andina, Siti Barokah, Oryz Agnu Dian Wulandari, Arista Apriani \\ Girsang dan Rizki Aprilia Nur Afifah \\ Universitas AMIKOM Purwokerto \\ Email: andina@amikompurwokerto.ac.id, siti.barokah@amikompurwokerto.ac.id, \\ oryzdian@amikompurwokerto.ac.id aprianiaristagirsang@gmail.com dan \\ rizkiaprilianurafifah@gmail.com
}

\begin{abstract}
The ecotourism concept promoted by mangrove forest of Kaliwlingi Village Brebes Regency is considered to be very interesting especially for the younger generation who not only want to travel but add the experience and education in it. The development of mangrove forest ecotourism in Kaliwlingi Village Brebes Regency is carried out seriously in addition to attracting more tourist as well as reducing poverty. With the concept of empowering the surrounding community, the ecotourism of mangrove forest in Kaliwlingi Village Brebes Regency continues to improve in order to become the number one tourist destination not only in Brebes Regency but Central Java Province. This type or research is descriptive qualitative research using interview methods and document studies. The results of research on the strategy of developing mangrove forest ecoutourism in Kaliwlingi Village Brebes Regency with various innovations that are proven to reduce poverty and improve the welfare of local community.
\end{abstract}

Keywords: Eocotourism; Strength; Poverty

\begin{abstract}
Abstrak
Konsep ekowisata yang diusung oleh hutan mangrove Desa Kaliwlingi Kabupaten Brebes dinilai sangat menarik terutama untuk generasi muda yang tidak hanya ingin berwisata namun juga ingin menambah pengalaman serta pendidikan di dalamnya. Pengembangan ekowisata hutan mangrove Desa Kaliwlingi Kabupaten Brebes dilakukan dengan serius disamping untuk lebih menarik minat wisatawan juga untuk mengurangi kemiskinan. Dengan konsep pemberdayaan masyarakat sekitar, ekowisata hutan mangrove Desa Kaliwlingi Kabupaten Brebes terus berbenah agar menjadi wisata nomor satu di Kabupaten Brebes bahkan di Provinsi Jawa Tengah. Jenis penelitian adalah penelitian kualitatif deskriptif dengan menggunakan metode wawancara dan studi dokumen. Hasil penelitian tentang strategi pengembangan ekowisata hutan mangrove Desa Kaliwlingi Kabupaten Brebes dengan berbagai inovasi yang terbukti bisa mengurangi kemiskinan serta meningkatkan kesejahteraan masyarakat setempat.
\end{abstract}

Kata kunci: Ekowisata; Kekuatan; Kemiskinan 
Anisa Nur Andina, Siti Barokah, Oryz Agnu Dian Wulandari, Arista Apriani Girsang dan Rizki Aprilia Nur Afifah

\section{Pendahuluan}

Kabupaten Brebes terletak di bagian Utara paling Barat Provinsi Jawa Tengah, di antara koordinat $108^{\circ}$ 41'37,7"-109 11'28,92" Bujur Timur dan 6 $6^{\circ} 44^{\prime} 56^{\prime} 5^{\prime \prime}-7^{\circ}$ 20'51,48 Lintang Selatan dan berbatasan langsung dengan wilayah Provinsi Jawa Barat. Menurut data BPS tahun 2016 Kabupaten Brebes mempunyai luas wilayah 166.296 $\mathrm{Km}^{2}$ dan memiliki jumlah penduduk sekitar 1.881.184 jiwa dengan kepadatan penduduk rata-rata sekitar 900,4 orang/Km².

Kabupaten Brebes terletak di bagian barat Provinsi Jawa Tengah. Wilayah Kabupaten Brebes terbagi menjadi 3 (tiga) dataran, yaitu wilayah pantai, wilayah tengah dan dataran tinggi. Kabupaten Brebes sebagai wilayah terluas kedua di Provinsi Jawa Tengah setelah Kabupaten Cilacap menjadikan Kabupaten Brebes mempunyai banyak tempat wisata yang tersembunyi dan belum banyak diketahui oleh masyarakat luas.

Keindahan alam Kabupaten Brebes menjadikan Kabupaten Brebes sebagai primadona penuh misteri. Dengan keadaan geografis yang meliputi dataran, pegunungan, lembah hingga pantai dan laut menyimpan potensi pariwisata yang luar biasa. Kabupaten Brebes bisa disebut sebagai Golden Triangle Tourism of Brebes atau segitiga emas pariwisata Brebes. Tiga wisata unggulan tersebut didukung oleh berbagai daya tarik wisata baik berupa wisata alam, budaya maupun wisata buatan.

Pariwisata artinya susunan organisasi, baik Pemerintah maupun swasta yang terkait dalam pengembangan, produksi, dan pemasaran produk suatu layanan yang memenuhi kebutuhan dari orang yang sedang bepergian. Sementara menurut UndangUndang Nomor 10 tahun 2009, pariwisata ialah berbagai macam kegiatan wisata yang didukung berbagai fasilitas serta layanan yang disediakan oleh masyarakat, pengusaha, Pemerintah serta Pemerintah Daerah.

Ekowisata mangrove Pandansari yang terletak di dukuh Pandansari desa Kaliwlingi Kecamatan Brebes Kabupaten Brebes semakin diperhitungkan sebagai kawasan wisata yang menyajikan pemandangan alam yang indah. Ekowisata hutan mangrove mulai dibuka untuk umum di tahun 2016 namun mulai menarik perhatian masyarakat di tahun 2017. Dengan semakin banyaknya pengunjung maka semakin banyak pula transaksi ekonomi yang terjadi disana.

Mangrove merupakan jenis tumbuhan maupun komunitas tumbuhan yang hidup di daerah perairan yang pasang surut. Hutan yang ditumbuhi mangrove sering disebut sebagai hutan bakau atau hutan payau. Disebut hutan bakau karena vegetasinya didominasi jenis bakau dan disebut hutan payau karena hutannya tumbuh diatas tanah yang selalu tergenang oleh air payau.

Dalam ekologi tumbuhan, mangrove digunakan untuk semak dan pohon yang tumbuh di daerah intertidal dan subtidal dangkal di rawa pasang tropika dan subtropika. Tumbuhan ini umumnya selalu hijau dan bisa mempunyai nilai ekonomis, industri maupun pariwisata.

Dengan dukungan berbagai elemen seperti pariwisata, kelautan dan perikanan, lingkungan hidup, kehutanan, pekerjaan umum serta instansi lainnya saat ini telah 
terwujud kawasan wisata yang memiliki daya tarik wisata tersendiri dan lain dari yang lain. Desa wisata Mangrove Pandansari menarik minat pengunjung tidak hanya dari Kabupaten Brebes namun juga dari beberapa kota besar seperti Jakarta, Bandung, Yogyakarta, Semarang dan banyak yang lainnya.

Awalnya penduduk desa Kaliwlingi sebagian besar berprofesi sebagai nelayan tambak karena wilayah mereka berada di pesisir pantai. Pada saat itu, tambak menjadi idola karena sangat menguntungkan dan penduduk menggantungkan hidup mereka dari tambak namun setelah beberapa tahun berjalan, abrasi atau kikisan air laut tidak bisa dihindari. Perlahan tambak milik penduduk digenangi air laut sampai tambak tidak bisa lagi beroperasi. Sampai akhirnya ada inisiatif untuk menanam mangrove untuk mengurangi abrasi.

Upaya penataan dan pengembangan ekowisata mangrove Desa Kaliwlingi Kabupaten Brebes ini merupakan sebuah terobosan untuk mengembangkan pariwisata yang terdapat di Kabupaten Brebes. Pengembangan ekowisata mangrove Desa Kaliwlingi Kabupaten Brebes diharapkan tak hanya meningkatkan kehidupan sosial ekonomi masyarakat sekitar namun juga dapat meningkatkan Pendapatan Asli Daerah (PAD) Kabupaten Brebes.

\section{Metode Penelitian}

Penelitian ini menggunakan jenis penelitian kualitatif dengan pendekatan deskriptif. Moleong mengatakan penelitian kualitatif adalah penelitian untuk memahami fenomena tentang apa yang dialami oleh subjek penelitian (Moleong, 2017). Sedangkan deskriptif kualitatif menurut Mukhtar adalah penelitian yang mendeskripsikan seluruh gejala atau keadaan yang ada yaitu keadaan dan gejala pada saat penelitian dilakukan (Mukhtar \& Pd, 2013). Deskriptif kualitatif melihat keadaan di lapangan pada saat penelitian berlangsung sehingga memudahkan peneliti untuk memperoleh data yang sesuai dengan kenyataan. Tujuan dari penelitian deskriptif ini adalah untuk membuat deskripsi, gambaran atau lukisan secara sistematis, faktual dan akurat mengenai faktafakta yang terjadi di lapangan serta hubungan antar fenomena yang sedang diselidiki.

Untuk pengumpulan data dilakukan dengan wawancara dan studi dokumen. Wawancara dilakukan secara terus menerus dengan narasumber supaya didapatkan hasil yang maksimal. Selain menggunakan wawancara, dilakukan juga observasi. Menurut Arifin observasi adalah proses pengamatan dan pencatatan secara sistematis, logis, objektif dan rasional mengenai berbagai fenomena baik dalam situasi yang sebenarnya maupun dalam situasi buatan untuk mencapai tujuan tertentu. Observasi dilakukan secara berkala untuk mendapatkan hasil yang maksimal (Zainal, 2011).

Selain menggunakan wawancara, pengumpulan data dalam penelitian ini juga menggunakan studi dokumen sebagai bahan triangulasi untuk mengecek keabsahan data. O'Leary mengatakan dalam hal ini, peneliti memperlakukan dokumen seperti informan yang memberikan informasi yang relevan kepada peneliti (O'Leary, 2014). Peneliti "mengajukan" pertanyaan kemudian mencari jawaban dalam dokumen. Teknik lain adalah mencatat kejadian, atau analisis konten, di mana peneliti mengukur 
Anisa Nur Andina, Siti Barokah, Oryz Agnu Dian Wulandari, Arista Apriani Girsang dan Rizki Aprilia Nur Afifah

penggunaan kata, frasa dan konsep tertentu. Pada dasarnya, peneliti menentukan apa yang sedang dicari, kemudian mendokumentasikan dan mengatur frekuensi dan jumlah kejadian dalam dokumen.

\section{Hasil dan Pembahasan}

\section{Pengertian dan Manfaat Ekowisata}

Konsep ekowisata menurut The International Ecotourism Society (2015) adalah perjalanan yang bertanggung jawab ke daerah-daerah alami yang melestarikan lingkungan, menopang kesejahteraan masyarakat setempat, melibatkan interprestasi serta pendidikan lingkungan hidup (Society, 2015).

Sementara menurut (Nugroho, 2011) ekowisata merupakan suatu perjalanan wisata yang bertanggung jawab pada kelestarian alam, budaya serta memuat unsurunsur edukasi. Dalam hal ini kita perlu menggaris bawahi tentang konsep ekowisata sebagai perjalanan yang bertanggung jawab sehingga sebagai pengelola maupun pengunjung, ekowisata tidak lepas dari upaya pelestarian lingkungan.

Beberapa aspek yang perlu diperhatikan dalam pengelolaan ekowisata adalah:

a. Menerapkan pola wisata ramah lingkungan

b. Menerapkan pola wisata ramah budaya dan adat setempat

c. Memberikan dampak secara langsung terhadap peningkatan perekonomian masyarakat setempat

d. Mendapatkan dukungan dari berbagai pihak terkait

e. Menjaga keharmonisan dengan alam

Manfaat ekowisata berdampak pada berbagai aspek. Manfaat tersebut meliputi :

a. Konservasi. Keterkaitan ekoturisme dengan satwa asli daerah tersebut sangat erat. Ikan glodok contohnya. Ikan glodok adalah ikan yang bentuk badannya hampir seperti lele atau ikan gabus. Ikan glodok hidup di perairan tropis dan subtropis, mereka hidup di tanah berlumpur, muara atau rawa mangrove. ikan glodok di lindungi dan pengunjung dilarang untuk mengambil ikan glodok tersebut.

b. Pemberdayaan ekonomi. Ekoturisme melibatkan masyarakat lokal berarti harus bisa meningkatkan kapasitas dan kesempatan kerja masyarakat lokal. Hal ini sudah terbukti di Ekowisata hutan mangrove Desa Kaliwlingi Kabupaten Brebes karena di lokasi ini sudah memberdayakan masyarakat lokal untuk berkarya baik dengan produk kuliner maupun kerajinan tangan.

c. Pendidikan lingkungan. Ekowisata hutan mangrove Desa Kaliwlingi Kabupaten Brebes juga menyediakan pendidikan lingkungan. Pendidikan merawat lingkungan harus ditanamkan sejak dini oleh karena itu banyak sekolah yang mengadakan kunjungan ke hutan mangrove Desa Kaliwlingi Kabupaten Brebes ini.

\section{Kondisi Internal}

Mangrove Pandansari terletak di Desa Kaliwlingi Kabupaten Brebes Provinsi Jawa Tengah. Mata pencaharian utama masyarakat Desa Kaliwlingi adalah nelayan. 
Pada awalnya mereka menggantungkan hidup dari upaya budidaya ikan, kepiting, hingga udang. Eksploitasi besar-besaran yang terjadi menimbulkan dampak ekosistem alam terganggu sehingga menyebabkan abrasi. Selebihnya adalah petani dan pedagang. Potensi produk dan daya tarik desa wisata mangrove Pandansari adalah modal dasar yang sangat penting untuk mendatangkan wisatawan.

Selain hutan mangrove, keindahan alam juga terlihat pada pulau pasir. Pulau pasir yang disebut oleh masyarakat sekitar tersebut sejatinya adalah tanah timbul berupa pasir laut dan berjarak sekitar 1,5 kilometer dari permukiman warga. Pulau pasir ini dapat terlihat saat air laut surut dan tenggelam kembali saat air laut pasang, keunikan inilah yang menjadi daya tarik tersendiri. Amanah mengatakan pembangunan di kawasan pesisir tidak lepas dari daya dukung lingkungan. Rendahnya taraf hidup masyarakat pesisir dan akses yang terbatas akan asset dan sumber-sumber pembiayaan bagi kehidupan pelayan merupakan persoalan utama yang dijumpai di kawasan pesisir (Amanah, 2010).

Dalam rangka peningkatan daya tarik wisata di ekowisata hutan mangrove Desa Kaliwlingi Kabupaten Brebes, masyarakat dan Pemerintah terus melakukan inovasi agar pengunjung yang datang merasakan puas dan diharapkan untuk datang kembali di kemudian hari.

\section{Promosi melalui media sosial}

Fasilitas umum yang ditawarkan pada ekowisata ini bertujuan untuk memperlancar kegiatan wisata. Secara umum ketersediaan fasilitas pendukung ini antara lain masjid, tempat makan, mushola, kamar mandi, lapangan parkir yang luas, sampai counter untuk mengisi pulsa. Selain itu disediakan pula perahu untuk menuju trekking mangrove sebanyak 10 buah yang bisa digunakan wisatawan hanya dengan membayar dua puluh ribu pada hari biasa dan dua puluh lima ribu rupiah pada hari libur nasional.

Dalam penelitian mereka, Leung dan kawan-kawan (2013) menunjukkan peran kunci media sosial dalam keputusan perjalanan. Mereka sadar bahwa konsumen umumnya menggunakan media sosial selama fase penelitian dari proses perencanaan perjalanan mereka (Leung, Law, Van Hoof, \& Buhalis, 2013). Oleh karena itu fasilitas umum harus terus ditingkatkan agar pengunjung yang datang senang dan bisa membagikan pengalaman mereka melalui media sosial. Hal itu menjadi semacam promosi gratis untuk obyek wisata. Di masa depan, pariwisata berorientasi internet akan menggunakan teknologi terintegrasi pelanggan yang lebih umum yang memungkinkan untuk berinteraksi dengan pengunjung secara interaktif (Buhalis, Leung, \& Law, 2011).

Pengunjung disediakan akses informasi pada obyek wisata oleh pengelola sehingga pengunjung tidak akan kesulitan saat berada di obyek wisata. Fasilitas pendukung juga dibagikan melalui sosial media sehingga pengunjung bisa lebih memahami apa saja yang terdapat pada obyek wisata hutan mangrove Pandansari tersebut. Pengunjung dapat mengakses informasi yang dapat dipercaya melalui sosial media dari sesama pengunjung. Selama proses pencarian informasi, 
Anisa Nur Andina, Siti Barokah, Oryz Agnu Dian Wulandari, Arista Apriani Girsang dan Rizki Aprilia Nur Afifah

pengunjung semakin mengandalkan tentang pengalaman wisata wisatawan lain yang dapat mengurangi ketidakpastian oleh karena itu pencarian informasi melalui sosial media karena media sosial merupakan tempat orang berinteraksi secara bebas dan mudah untuk bertukar informasi (Fotis, Buhalis, \& Rossides, 2012).

Penelitian yang dilakukan oleh (Gretzel \& Fesenmaier, 2016) menunjukkan bahwa hubungan yang dibentuk melalui media sosial dengan obyek wisata berfokus pada informasi dan mengekspresikan keterikatan emosional. Perbedaan seperti itu harus diakui dan diperhitungkan saat memutuskan strategi pemasaran.

Sigala, dkk (2012) membedakan antara tinggi rendahnya saluran promosi yang tersedia. Semakin banyak tautan media sosial dan semakin seringnya pengunjung melakukan posting pada media sosial membuat sinergi yang baik untuk mendapatkan target pasar yang lebih (Sigala, Christou, \& Gretzel, 2012).

\section{Daya Tarik Ekowisata Hutan Mangrove Pandansari}

\section{Tabel 1 Daya Tarik Ekowisata Hutan Mangrove Pandansari}

\begin{tabular}{cl}
\hline \multicolumn{1}{c}{ Daya Tarik Wisata } & \multicolumn{1}{c}{ Keterangan } \\
\hline a. Daya tarik wisata alam & 1. Hutan mangrove \\
& 2. Satwa burung dan ikan glodok \\
& 3. Pembibitan mangrove \\
& 4. Pulau pasir \\
& 5. Olahraga air \\
& 6. Pemancingan ikan \\
& 7. Batik mangrove \\
\hline b. Daya tarik wisata budaya & 1. Rajah Bumi \\
& 2. Merti Bumi \\
& 3. Sedekah Laut \\
& 4. Calung \\
& 5. Sintren \\
\hline c. Daya tarik wisata religi & 6. Burok \\
& 1. Petilasan Mbah Pandan \\
& 2. Sumur dalem Demang Sapingi \\
& 3. Ritual Dewi Lanjar dan Rantam Sari \\
& 4. Kungkum pesisir Pandansari \\
& 5. Ujung Kitiran \\
\hline d. Daya tarik wisata kuliner & 1. Kuliner laut ikan, udang, kerang \\
& 2. Kue mangrove \\
& 3. Jipang dan legram \\
\hline
\end{tabular}

\section{Dukungan Kuat dari Masyarakat}

Berdasarkan hasil wawancara dan observasi langsung yang dilakukan oleh peneliti menunjukkan bahwa rata-rata masyarakat Desa Kaliwlingi mendukung penuh pembentukan Desa Wisata terutama dari pokdarwis (Kelompok Sadar Wisata). Pokdarwis adalah lembaga yang didirikan warga yang anggotanya terdiri dari para pelaku kepariwisataan yang memiliki kepedulian dan tanggung jawab 
serta berperan sebagai penggerak untuk menciptakan iklim yang kondusif bagi perkembangan pariwisata di wilayah desa mereka serta mewujudkan sapta pesona.

Muljadi (2014) mengatakan bahwa masyarakat merupakan pelaku aktif dalam kegiatan kepariwisataan yang bertujuan untuk meningkatkan kesejahteraan masyarakat dan kepariwisataan merupakan aktualisasi dari sistem ekonomi kerakyatan yang merupakan kegiatan seluruh lapisan masyarakat Indonesia sebagai sumber ekonomi kreatif masyarakat (Muljadi, 2014).

Harsono dan rekan (2019) mengatakan pembinaan yang intensif, sumber daya manusia yang ada dapat didorong untuk terlibat aktif dalam pembentukan kampong wisata sehingga usia produktif bisa ikut memanfaatkan potensi dan membangun desa tanpa perlu mencari pekerjaan di luar kota (Harsono \& Suhandi, 2019).

Desa Kaliwlingi saat ini lebih dikenal masyarakat luas karena memanfaatkan sosial media sebagai tempat untuk promosi. Tidak hanya melalui Facebook tetapi juga Instagram. Secara berkala Instagram Dinas Kebudayaan dan Pariwisata Kabupaten Brebes memposting tempat-tempat wisata yang terdapat di Kabupaten Brebes. Melalui sosial media juga masyarakat luas mengetahui tentang event yang akan dilaksanakan di obyek wisata.

Ekowisata hutan mangrove Pandansari Desa Kaliwlingi Kabupaten Brebes menawarkan banyak spot selfie yang kekinian untuk digunakan oleh anak-anak muda. Dengan adanya spot selfie ini, anak-anak muda diharapkan bisa memposting kunjungan mereka ke obyek wisata di sosial media mereka masing-masing. Ini digunakan sebagai promosi gratis karena sosial media memberikan efek yang luar biasa dalam peningkatan kunjungan wisatawan.

Pengelola melakukan perubahan spot selfie secara berkala dengan tujuan pengunjung tidak bosan karena spot selfie yang selalu baru maka akan menarik baik pengunjung lama maupun pengunjung baru yang penasaran dengan hal tersebut. Disamping itu banyaknya warga yang sudah menggunakan sosial media dan sering memposting tentang keindahan hutan mangrove Desa Kaliwlingi Kabupaten Brebes membuat minat pengunjung menjadi meningkat.

Hidayah (2013) mengatakan dibutuhkan peran aktif masyarakat pada keseluruhan proses pembagunan sehingga akan tercipta sinergi yang baik antara masyarakat dengan Pemerintah serta kalangan yang berpartisipasi (Hidayah, 2013).

\section{Tingkat Kemiskinan Berkurang}

Ekowisata hutan mangrove Pandansari Desa Kaliwlingi Kabupaten Brebes ini telah memberikan manfaat yang besar bagi warga desa terutama dalam hal infrastruktur dan ekonomi. Infrastruktur menjadi jauh lebih baik, akses jalan menuju kawasan ekowisata pun sudah jauh lebih mudah dibandingkan sebelum adanya obyek wisata. Ekonomi warga desa menjadi lebih baik dari yang awalnya hanya petani dan nelayan sekarang banyak yang beralih menjadi pekerja di obyek wisata.

Warung-warung yang tersedia di obyek wisata juga milik warga lokal. Mereka tidak mengizinkan pendatang atau orang asing untuk berjualan karena 
Anisa Nur Andina, Siti Barokah, Oryz Agnu Dian Wulandari, Arista Apriani Girsang dan Rizki Aprilia Nur Afifah

mereka ingin mengkaryakan warga lokal terlebih dahulu. Kesejahteraan warga Desa Kaliwlingi sangat diperhatikan dengan baik sehingga tercipta sinergi sehingga semakin banyak yang tertarik untuk berkunjung. Warga Desa Kaliwlingi sangat terbantu dengan adanya ekowisata hutan mangrove karena mereka bisa mendapatkan tambahan penghasilan selain dari melaut dan bertani.

Kerajinan khas Desa Kaliwlingi menjadi daya tarik wisata yang tidak ditemukan di tempat lain membuat warga lokal berbondong-bondong untuk berkarya. Batik mangrove contohnya, batik ini menjadi batik khas yang hanya ada di desa Kaliwlingi. Batik ini mempunyai corak mangrove khas pesisir dengan pewarna alami menggunakan tinta dari bahan mangrove.

Batik mangrove merupakan salah satu bentuk kearifan budaya lokal. Memanfaatkan mangrove yang sudah mati untuk dijadikan tinta menjadikan batik mangrove sebagai batik alami yang ramah lingkungan karna tidak memakai bahan sintetis. Proses pembuatan batik mangrove yang memakan waktu lima hingga tujuh hari menyebabkan batik ini sangat diminati oleh pengunjung karena keunikannya. Batik mangrove dikenal unik karena motifnya yang berbeda dengan motif batik yang tidak bisa ditemukan di tempat lain. Selain batik mangrove, terdapat juga kerajinan dari bahan kulit kerang.

\section{Peluang}

Masyarakat dan Pemerintah Kabupaten terus berusaha untuk meningkatkan kualitas ekowisata hutan mangrove Desa Kaliwlingi supaya semakin banyak pengunjung yang datang untuk berwisata. Pada tahun 2018 tercatat sekitar enam ribu orang datang berkunjung setiap harinya pada musim libur lebaran sementara pada tahun 2019 tercatat sepuluh ribu orang datang berkunjung setiap harinya pada musim libur lebaran. Pada hari minggu bisa tercatat sekitar seribu orang datang berkunjung.

Dengan banyaknya spot selfie yang ditawarkan serta pemandangan yang indah bahkan menarik pasangan untuk melakukan sesi foto pre-wedding disana. Hal ini tentu saja menjadi peluang yang baik untuk pengelola supaya bisa menyediakan lebih banyak spot selfie yang menarik terutama untuk pasangan dan keluarga.

Seiring dengan perkembangan Ekowisata hutan mangrove Desa Kaliwlingi Kabupaten Brebes yang sangat pesat serta peningkatan jumlah kunjungan wisatawan menjadi catatan tersendiri bagi seluruh pengelola maupun instansi Pemerintah, pihak swasta dan pokdarwis agar semakin berbenah menjadikan sapta pesona menjadi kunci utama dalam pengembangan kepariwisataan.

\section{Kesimpulan}

Berdasarkan hasil pembahasan yang telah diuraikan maka dapat ditarik kesimpulan sebagai berikut:

Pertama, pengembangan yang dilakukan oleh ekowisata hutan mangrove Desa Kaliwlingi Kabupaten Brebes semakin menuai hasil yang baik terlihat dari semakin 
banyaknya pengunjung yang datang baik di akhir pekan, hari biasa terlebih pada musim liburan. Pihak pengurus ekowisata hutan mangrove Desa Kaliwlingi Kabupaten Brebes gencar melakukan promosi di media sosial dan mengganti suasana ekowisata hutan mangrove Desa Kaliwlingi Kabupaten Brebes secara berkala supaya masyarakat yang datang tidak bosan pada kunjungan berikutnya.

Kedua, meningkatkan perekonomian masyarakat sekitar karena ekowisata hutan mangrove Desa Kaliwlingi Kabupaten Brebes ini hanya memberdayakan masyarakat sekitar untuk berjualan di ekowisata hutan mangrove Desa Kaliwlingi Kabupaten Brebes.

Ketiga, upaya pemberdayaan masyarakat sekitar melalui pembuatan makanan khas serta produk khas ekowisata hutan mangrove Desa Kaliwlingi Kabupaten Brebes yang tidak bisa ditemukan di tempat lain seperti batik mangrove.

Dengan adanya ekowisata hutan mangrove Desa Kaliwlingi Kabupaten Brebes yang terus melakukan inovasi, diharapkan pengunjung akan terus datang dan tidak merasa bosan hal ini bisa lebih meningkatkan perekonomian warga. 
Anisa Nur Andina, Siti Barokah, Oryz Agnu Dian Wulandari, Arista Apriani Girsang dan Rizki Aprilia Nur Afifah

\section{BIBLIOGRAFI}

Amanah, Siti. (2010). Peran komunikasi pembangunan dalam pemberdayaan masyarakat pesisir. Jurnal KMP (Jurnal Komunikasi Pembangunan), 8(1).

Buhalis, Dimitrios, Leung, Daniel, \& Law, Rob. (2011). eTourism: critical information and communication technologies for tourism destinations. Destination Marketing and Management: Theories and Applications, 2011, 205-224.

Fotis, John N., Buhalis, Dimitrios, \& Rossides, Nicos. (2012). Social media use and impact during the holiday travel planning process. Springer-Verlag.

Gretzel, Ulrike, \& Fesenmaier, Daniel R. (2016). Customer relations 2.0-implications for destination marketing.

Harsono, Pramudi, \& Suhandi, Suhandi. (2019). Strategi Pengembangan Kampung Wisata Untuk Mengurangi Urbanisasi (Studi Kasus Kampung Cinyurup Kelurahan Juhut Kecamatan Karangtanjung Kabupaten Pandeglang). Jurnal Manajemen STIE Muhammadiyah Palopo, 5(2).

Hidayah, R. D. (2013). Pemberdayaan Masyarakat Untuk Memajukan Desa Wisata Pentingsari Kecamatan Cangkringan Kabupaten Sleman Daerah Istimewa Yogyakarta.[Internet].[diunduh pada 26 desember 2017]. Dapat Diunduh Dari: Http://Eprints. Uny. Ac. Id/18096.

Leung, Daniel, Law, Rob, Van Hoof, Hubert, \& Buhalis, Dimitrios. (2013). Social media in tourism and hospitality: A literature review. Journal of Travel \& Tourism Marketing, 30(1-2), 3-22.

Moleong, Lexy J. (2017). Metode Penelitian Kualitatif, cetakan ke-36. Bandung: PT. Remaja Rosdakarya Offset.

Mukhtar, P. D., \& Pd, M. (2013). Metode Praktis Penelitian Deskriptif Kualitatif. Jakarta: GP Press Group.

Muljadi, A. J. (2014). Kepariwisataan Dan Perjalanan. Bandung: Rajawali Pers.

Nugroho, Iwan. (2011). Ekowisata dan pembangunan berkelanjutan. Pustaka Pelajar.

O'Leary, Z. (2014). Primary data: Surveys, interviews and observation. The Essential Guide to Doing Your Research Project, 201-216.

Sigala, Marianna, Christou, Evangelos, \& Gretzel, Ulrike. (2012). Social media in travel, tourism and hospitality: Theory, practice and cases. Ashgate Publishing, Ltd.

Society, The International Ecotourism. (2015). TIES Announces Ecotourism Principles Revision. Retrieved from http://www.ecotourism.org/news/tiesannounces- 
Strategi Pengembangan Ekowisata Hutan Mangrove Pandansari Kabupaten Brebes Untuk Mengurangi Kemiskinan

ecotourism-principles-revision

Zainal, Arifin. (2011). Evaluasi Pembelajaran Prinsip, Teknik, Prosedur. Bandung: PT Remaja Rosdakarya. 